\title{
Investigation of plant sources of hydroperoxide lyase for 2(E)-hexenal production
}

\author{
L'ubomír Činčala a , Viera Illeováa, Monika Antošováa, \\ Vladimír Štefuca ${ }^{\text {b }}$ Milan Polakovič ${ }^{\mathrm{a}}$ \\ ${ }^{a}$ Department of Chemical and Biochemical Engineering, \\ Institute of Chemical and Environmental Engineering, \\ Faculty of Chemical and Food Technology, Slovak University of Technology, \\ Radlinského 9, 81237 Bratislava, Slovakia \\ ${ }^{b}$ Axxence Slovakia, s.r.o., Mickiewiczova 9, 81107 Bratislava \\ milan.polakovic@stuba.sk
}

\begin{abstract}
E)-hexenal is a green note flavour molecule that is widely used in various compositions of aromas, flavours and perfumery. As there is considerable demand for naturally produced aromas this article deals with some aspects of this C6-volatile production with regard to the selection of plant source material and reaction conditions. The following plants were tested for this purpose: runner bean (Phaseolus coccineus), common bean (Phaseolus vulgaris), three (Capsicum annuum) bell pepper varieties, garden cress (Lepidium sativum), green slicing cucumber (Cucumis sativa), mung beans (Vigna mungo) and brown lentils (Lens culinaris). Selection of source material was considered on the basis of 2(E)-hexenal yield and productivity. The common bean leafs were able to produce up to $35 \mathrm{mg}$ of 2(E)-hexenal/ $\mathrm{kg}$ fresh leaves.
\end{abstract}

Keywords: 2(E)-hexenal, hydroperoxide lyase, linolenic acid, lipoxygenase, C6 volatiles, green note

\section{Introduction}

2(E)-hexenal (also called trans-2-hexenal or leaf aldehyde) is a naturally occurring unsaturated aldehyde. It is a colourless liquid with sharp acrolein pungency (Surburg and Panten, 2006) which on dilution smells pleasantly green. In vivo its production is induced as a stress response to plant wounding (Gigot et al., 2010) and is speculated to serve as a chemical alert to other plants and a defence against microbial pathogens and insects (Gomi et al., 2003). There are also hypotheses of fungicide effect and predatory insect attractant functions (Grechkin, 2002; Fauconnier and Marlier, 1997; Liu and Han, 2010). 2(E)-hexenal can be found in many species of fruits, leaves and vegetables (including freshly cut grass, cucumbers, green apples, watermelon, alfalfa, buckwheat, soybean seeds, pear, kidney bean, spinach leaves and other many other plants and foliage (Janeš et al., 2009; Grechkin, 2002; Bourel et al., 2004; Fauconnier and Marlier, 1997; Buchhaupt et al., 2012) and is a major component of ripe tomato aromatic profile (Havkin-Frenkel and Belanger, 2008). C6 volatiles also contribute considerably to cut green-apple smell (Surburg and Panten, 2006). As a perspective natural source of substrates for C6 volatiles production, enzymatically hydrolysed linseed oil seems to be an attractive option because of high content of linoleic and linolenic acids (Rehbocket al., 1998).
Natural biosynthetic pathway of green leaf volatiles begins with liberation of unsaturated C18 fatty acids from acyl glycerols by hydrolases or lipases into their free form. This cascade is initiated by tissue disruption (Grechkin, 2002) and proceeds rapidly. Oxygen is inserted into fatty acid molecule by action of lipoxygenase (LOX) on C-9 or C-13 carbon of the fatty acid. A split catalysed by hydroperoxide lyase (HPL) follows as shown in the reaction (Fig. 1). The product of this enzymatic cascade is an unsaturated aldehyde, which may be consequently partly isomerised into other aldehydes or reduced into alcohols. Depending on the plant, the products can be either C6 and/or C9 compounds. The developed mixture of these compounds in different ratios contributes to the odour profile, which is characteristic for each plant. Aside from hydroperoxide lyase, fatty acid hydroperoxides are also subject to other enzymes of the oxylipin pathway, for example, allene oxide synthase and divinyl ether synthase.

Lipoxygenase (LOX) is an oxidoreductase acting on single donors with incorporation of one molecule of oxygen into (poly)unsaturated fatty acid molecules. A common characteristic of these fatty acids is that they contain a 1,4-pentadiene structure sequence in their molecule. This structural moiety is the basis for oxygen insertion. The sources for lipoxygenase are wide - soybean, corn, tomato fruits, potato tuber, barley seed, wheat germ, pea seeds and other (Gardner, 1996). 

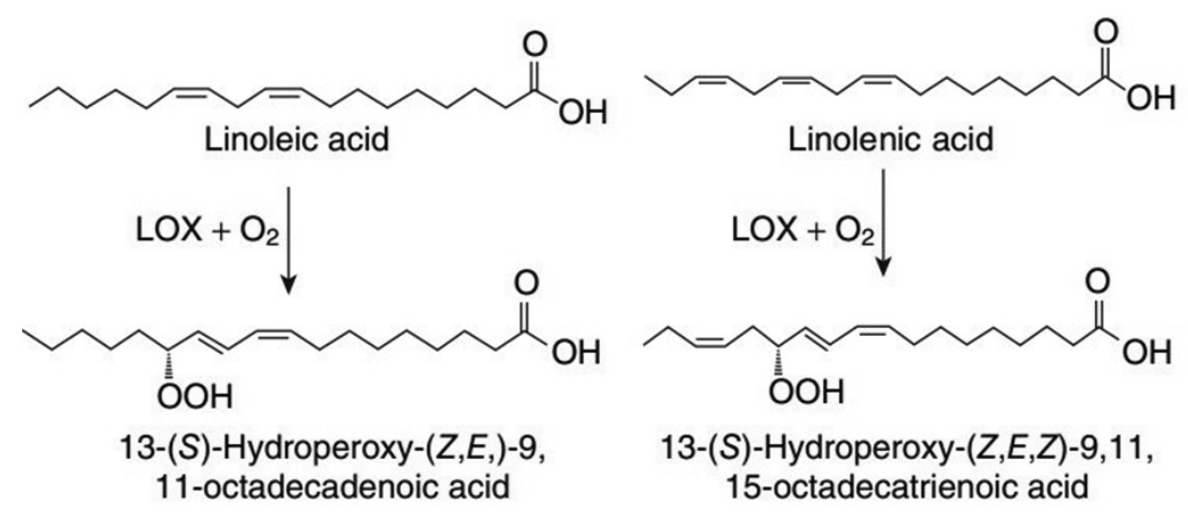

13-(S)-Hydroperoxy-(Z,E,Z)-9,11, 15-octadecatrienoic acid
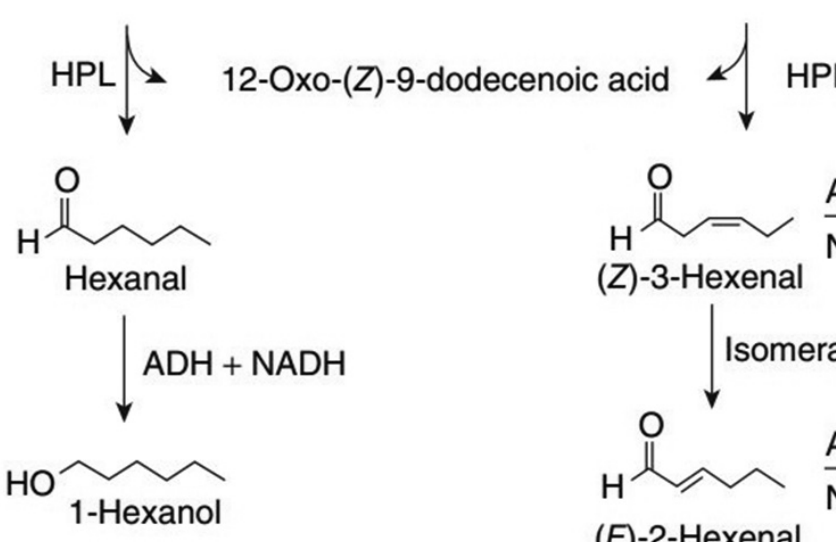
- Lens culinaris (brown lentils) were soaked in tap water for 2 days, and, then they were transferred to moist wool to allow germination for 4-6 days.

- Cucumis sativus (green cucumber, slicing) was bought from a local store and used in this form.

- Phaseolus coccineus and Phaseolus vulgaris (runner bean and common bean, respectively) were soaked for 2 days in tap water with no additives. After soaking, they were transferred to moist wool for germination for 3-5 days. Germinating seeds were then transferred to a flowerpot with unmodified general gardening earth from a local store. Seedlings were then wetted every second day and allowed to grow under normal daily lightning conditions during the spring and summer season. The plants were provided with support for creeping vines. The leaves were harvested no sooner than after 3 weeks after planting.

\section{Hydroperoxide preparation}

0.5-1 g of oil substrate (either LiA, LeA or Nouracid LE80) was emulsified with $5 \mathrm{~g}$ of $10 \%$ Tween-20 in and ultrasonic bath and $100 \mathrm{ml}$ of borate buffer (0.1 M; pH 9.6) was added. Vigorous bubbling with air or oxygen was provided. The reaction vessel was kept at $4{ }^{\circ} \mathrm{C}$. Lipoxygenase reaction was started by addition of $0.01-0.1 \mathrm{~g}$ of commercial 13-lipoxygenase. Samples for HPLC were taken during the reaction at different times. After the reaction was finished, the whole content of reaction vessel was extracted twice with same volume of diethyl ether. The organic phase was separated by centrifugation and solvent was evaporated by flushing with nitrogen. Some remaining water was also dried out by the nitrogen stream. $0.01-0.5 \mathrm{~g}$ of the oily extract was then mixed with $3 \mathrm{ml}$ of phosphate buffer $(0.1 \mathrm{M}$; pH 6.5) and $30 \mathrm{ml}$ of $10 \%$ Tween-20 and emulsified in ultrasound. This hydroperoxide emulsion was used with plant homogenate as a substrate. The content of hydroperoxides was determined by HPLC.

\section{Plant homogenisation}

Plant samples were homogenised using a Polytron PT-MR 2500E device (Kinematica, Luzern, Switzerland). Larger plants (bean leafs, pepper, cucumber) were pre-cut into pieces with the size about $1 \times 3 \mathrm{~cm}$. The plant material was homogenised on ice for 3-5 min at $20000 \mathrm{rpm}$ in a phosphate buffer (0.1 M; pH 6.5) pre-cooled to $4{ }^{\circ} \mathrm{C}$ and containing $3 \mathrm{mmol} / \mathrm{l} \mathrm{Na} \mathrm{N}_{2}$ EDTA, $0.5 \% \mathrm{w} / \mathrm{w}$ Triton X-100, $0.5 \% \mathrm{w} / \mathrm{w}$ PVP and $5-15 \mathrm{mmol} / 1$ DTT. The biomass and buffer were used in a ratio $3 \mathrm{~g}$ per $10 \mathrm{ml}$. The homogenate was filtered through a cheesecloth and used as a source of HPL enzyme.

\section{Hexenal production}

The filtered plant homogenate was added to the hydroperoxide emulsion (10:1 v/v) into sealed vials and mixed on shaker for $30 \mathrm{~min}$ at room temperature. After the reaction was complete, a sample was taken from each vial and extracted once with ethyl acetate $(1: 1 \mathrm{v} / \mathrm{v})$ for $30 \mathrm{~min}$. After centrifugation, the organic phase was separated. 2-ethyl-butanol diluted in 2-propanol was added to the ethylacetate extract as an internal standard, dried by anhydrous $\mathrm{Na}_{2} \mathrm{SO}_{4}$ and analysed by GC. In all experiments with biomass, parallel setups were performed when the hydroperoxide concentration in the emulsion was zero to quantify endogenously formed 2(E)-hexenal.

\section{HPLC measurements}

Samples from lipoxygenase reaction were measured by high-performance liquid chromatography system Agilent 1100/1200 equipped with a Zorbax Eclipse XDB-C18 reversed-phase column $(4.6 \times 150 \mathrm{~mm})$ maintained at $30^{\circ} \mathrm{C}$ and a diode array detector (PerezGilabert, 2002; Liu, 2010). Reaction products were monitored at $192 \mathrm{~nm}$ (for fatty acids) and $234 \mathrm{~nm}$ (for hydroperoxides). The following elution gradient was used: $0-8.5 \mathrm{~min}$ from $55 \%$ to $70 \%$ of $\mathrm{B}$, $8.5-11.5 \mathrm{~min}$ from $70 \%$ to $95 \%$ of $\mathrm{B}, 11.5-15.5 \mathrm{~min}$ $95 \%$ of $\mathrm{B}$ at a flow rate of $1.2 \mathrm{ml} / \mathrm{min}$. The mobile phase A was purified filtered water with $1 \mathrm{ml} / 1$ glacial acetic acid and mobile phase $\mathrm{B}$ was pure acetonitrile with $1 \mathrm{ml} / 1$ glacial acetic acid. 13-hydroperoxides of fatty acids used as external standards for calibration were provided by Axxence Slovakia (Bratislava, Slovakia).

\section{GC assay}

2(E)-hexenal content was measured using Agilent 7890A gas chromatograph with a DB-Wax polyethylene glycol column $(0.32 \mathrm{~mm} \times 0.50 \mu \mathrm{m}$ film $\times 30 \mathrm{~m})$ and flame ionisation detector. Carrier gas was hydrogen with the inlet pressure of $50 \mathrm{kPa}$. Column temperature gradient elution mode was used with column starting at $75^{\circ}$ for $2 \mathrm{~min}$, from $75^{\circ} \mathrm{C}$ to $100{ }^{\circ} \mathrm{C}$ with $6{ }^{\circ} \mathrm{C} / \mathrm{min}$ then held for $3 \mathrm{~min}$. The inlet temperature was $220^{\circ} \mathrm{C}$ with the sample injection volume of $10 \mu \mathrm{L}$ and split mode (1 : 50). 2-ethyl-1butanol was used as an internal standard. Owing to $1: 1$ extraction, the determined concentration of 2(E)-hexenal in the extract was the same as it was in the reaction mixture.

\section{Results and discussion}

\section{Plant screening for HPL activity}

The lipoxygenase reaction is the first step in 2(E)hexenal production. Our first task was to optimise 
reaction conditions for hydroperoxide formation. The substrate concentrations tested ranged from 5 to $10 \mathrm{~g} / 1$ of oily substrate (linoleic, linolenic acids or Nouracid LE80 mixture) while the amount of enzyme used ranged from 0.4 to $5 \mathrm{U}$. With the commercial Nouracid LE80 fatty acid mixture, we were able to reach conversions of LiA and LeA up to $70 \%$. However, there were impurities which contributed to the total oil concentration but were not a substrate for lipoxygenase. In case of pure LiA and LeA, the conversions were nearly $100 \%$. Fig. 2 presents a time-course of reaction progress in the case when Nouracid LE80 was used as a substrate for lipoxygenase. An important factor in the LOX transformation is the supply of oxygen. In otherwise similar conditions, higher hydroperoxide concentrations in less time could be achieved with supplying pure oxygen instead of air.

In hexenal production experiments, various plants were examined for their ability to produce C6-volatiles. The preliminary test was focused on finding a plant material that is able to produce appreciable amounts of 2(E)-hexenal. Tab. 1 summarizes the results of these experiments when the substrate was 13-hydroperoxide of linolenic acid (13-HPOT). A substantial part of 2(E)-hexenal was formed endogenously from plant homogenate. The values given in Table 1 represent the sum of both endogenous and exogenous product. The evolution of hydroperoxides during homogenisation or their addition caused fast inactivation of hydroperoxide lyase. For that reason, it was essentially impossible to

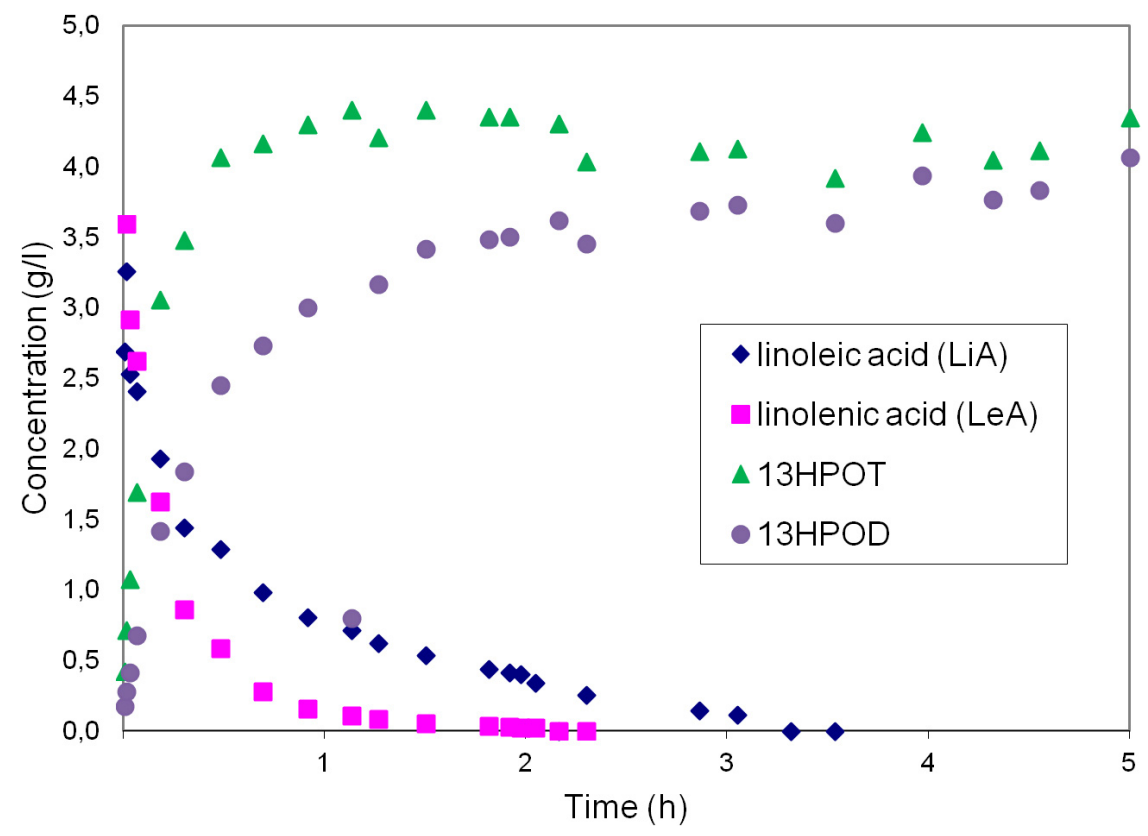

Fig. 2. Lipoxygenase reaction progress. Substrate was Nouracid LE80 (9.47 g/l) and $2.63 \mathrm{U}$ of LOX was used. Total volume was $100 \mathrm{ml}$.

Tab. 1. Results of plant screening for HPL activity.

\begin{tabular}{lccc}
\hline \multirow{2}{*}{ Plant material } & $\begin{array}{c}\text { 2(E)-hexenal concentration in extract } \\
\mathrm{mg} / \mathrm{l}\end{array}$ & $\begin{array}{c}\text { 13-HPOT concentration } \\
\mathrm{mg} / \mathrm{l}\end{array}$ & \multicolumn{2}{c}{ 2(E)-hexenal formed } \\
\hline Common bean & 7.38 & 5.5 & 22.1 \\
Bell pepper 1 & 0.56 & 6.5 & 1.7 \\
Bell pepper 2 & 0.23 & 5.7 & 0.7 \\
Bell pepper 3 & 0.30 & 6.4 & 0.9 \\
Runner bean leaf & 7.52 & 3.5 & 42.1 \\
Garden cress & $\mathrm{n} / \mathrm{d}$ & 2.2 & $\mathrm{n} / \mathrm{d}$ \\
Cucumber & 5.07 & 22.4 & 10.1 \\
Lentil seedlings & 1.27 & 28.8 & 2.54 \\
Mung bean seedlings & 4.18 & 31.3 & 8.35 \\
\hline
\end{tabular}

$\mathrm{n} / \mathrm{d}-$ not detectable. 
distinguish between the endogenous and exogenous product. In further experiments presented below, a blank experiment was carried out that provided the value of endogenous product concentration. It is however only a reference value because it does not incorporate the inactivation effect of added hydroperoxide substrate. Based on these observations, mung bean seedlings and runner bean leaves were selected for further experiments. A typical chromatogram of the reaction extract sample is shown in Fig. 3.

\section{Substrate type and concentration effect}

To compare the effect of different substrates on the quantity of C6-volatile products, different substrate types were tested using bean leaf and mung bean seedlings as the HPL source. The substrates sources were unmodified Nouracid LE80 that contains both linoleic and linolenic acids, diluted in a phosphate buffer solution (PBS) to a concentration of $9 \mathrm{~g} / 1$ and 13-HPOT made from pure linolenic acid diluted in PBS $(0.3 \mathrm{~g} / \mathrm{l})$. The homogenisation buffer without substrate (PBS) was also used as a blank standard. In all trials, $5 \mathrm{ml}$ of biomass homogenate was used. The results are given in Table 2. In case of bean leaf, almost no difference in the behaviour of the enzyme system could be observed while using either no substrate or fatty acids. However, the addition of 13-HPOT caused a rise in 2(E)-hexenal concentration and a drop in 1-hexanol concentration, indicating a preference of HPL for the 13-HPOT instead of endogenous 13-HPOD. The situation was however different for mung bean seedlings. The concentration of 1-hexanol was very similar in all three cases while the addition of fatty acids activated also the lipoxygenase system that created 13-HPOT and led to the formation of 2(E)-hexenal.

In the next step, a wider range of 13-HPOT substrate concentrations was examined for selected plants as HPL sources. Those plants were mung bean seedlings, runner bean leafs, lentil seedlings and slicing cucumber. The results of the formation of both products of HPL action, 2(E)-hexenal and 1-hexanol, are presented in Figs. 4 and 5. In case of 1-hexanol, there does not seem to be a rising trend in concentrations as there was no substrate provided (13-HPOD) that would convert to

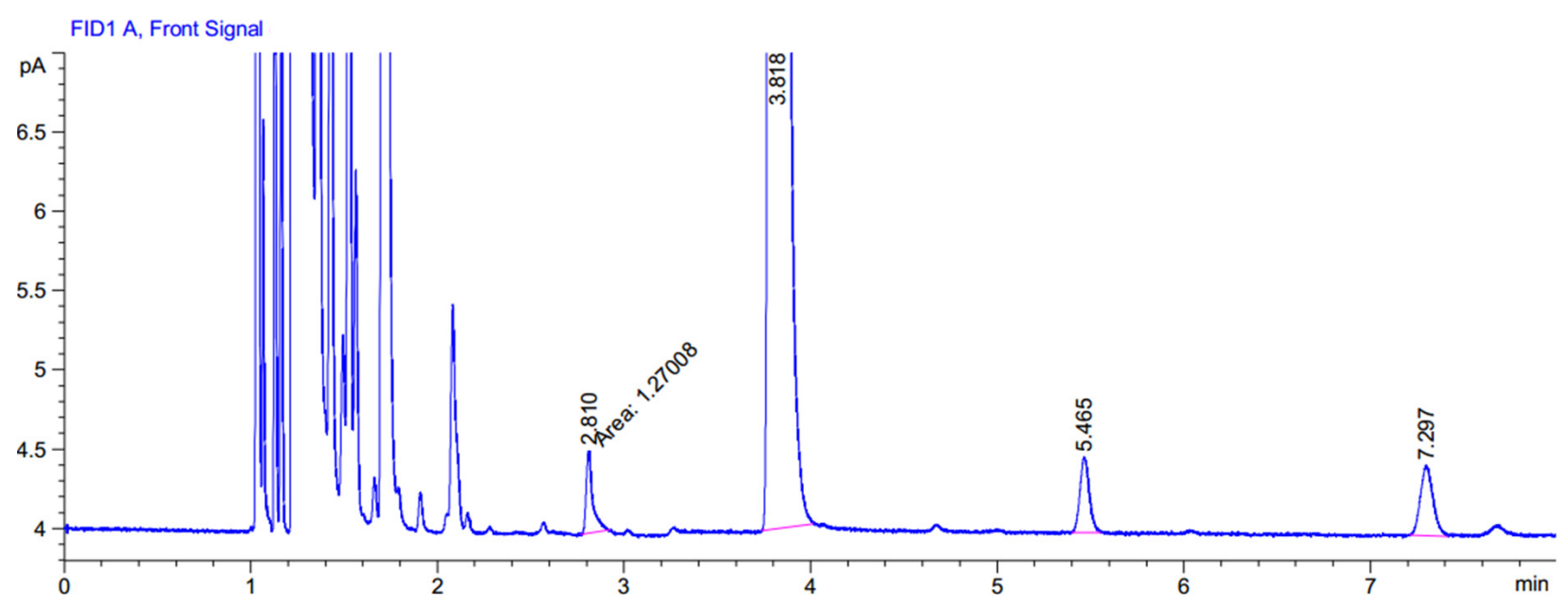

Fig. 3. GC analysis of the volatiles extract (Retention times in min: $2.809-2(\mathrm{E})$-hexenal, 3.787 - 2-ethyl-1-butanol internal standard, 5.427 - 3(Z)-hexenol, 7.252 - 1-octen-3-ol, other peaks unidentified).

Tab. 2. Comparison of HPL activity for different substrates.

\begin{tabular}{lccccc}
\hline Plant material & $\begin{array}{c}\text { PBS } \\
\mathrm{ml}\end{array}$ & $\begin{array}{c}\text { Nouracid } \\
\mathrm{ml}\end{array}$ & $\begin{array}{c}\text { 13-HPOT } \\
\mathrm{ml}\end{array}$ & $\begin{array}{c}\text { 2(E)-hexenal } \\
\mathrm{mg} / \mathrm{l}\end{array}$ & $\begin{array}{c}\text { 1-hexanol } \\
\mathrm{mg} / \mathrm{l}\end{array}$ \\
\hline Runner bean leaf & 2 & 0 & 0 & 37.0 & 82.0 \\
Runner bean leaf & 0 & 2 & 0 & 38.5 & 84.8 \\
Runner bean leaf & 0 & 0 & 2 & 64.5 & 68.5 \\
Mung bean seedlings & 2 & 0 & 0 & 0.5 & 34.1 \\
Mung bean seedlings & 0 & 2 & 0 & 13.5 & 29.9 \\
Mung bean seedlings & 0 & 0 & 2 & 12.6 & 33.1 \\
\hline
\end{tabular}




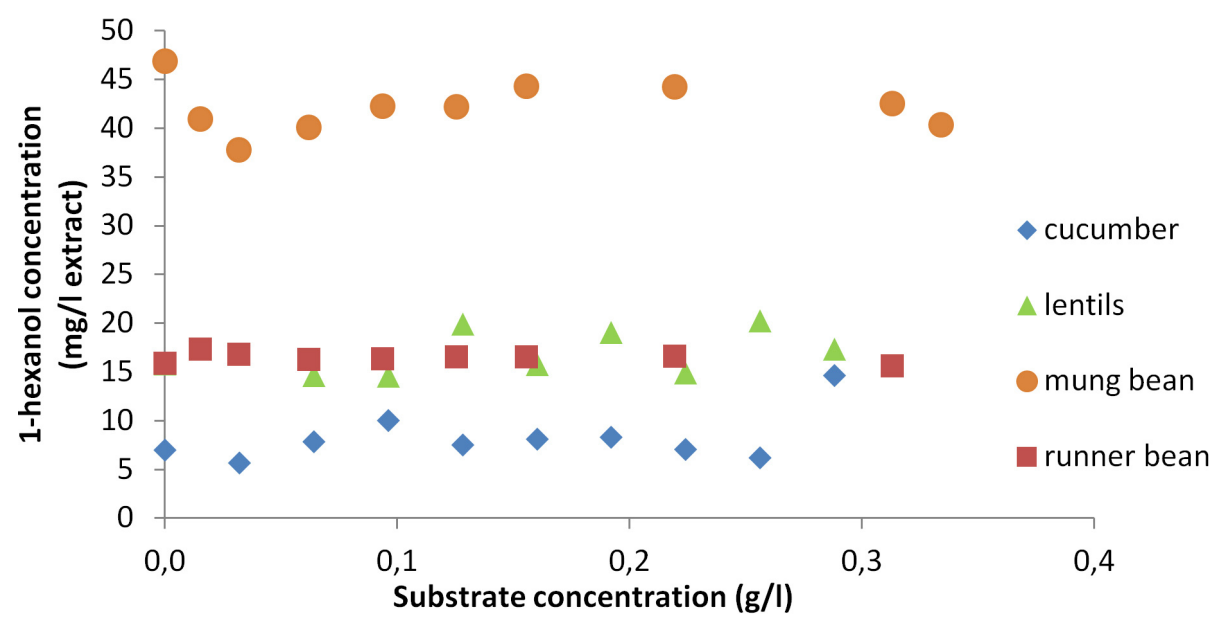

Fig. 4. Formation of 1-hexenol concentration in dependence on substrate concentration (13-HPOT).

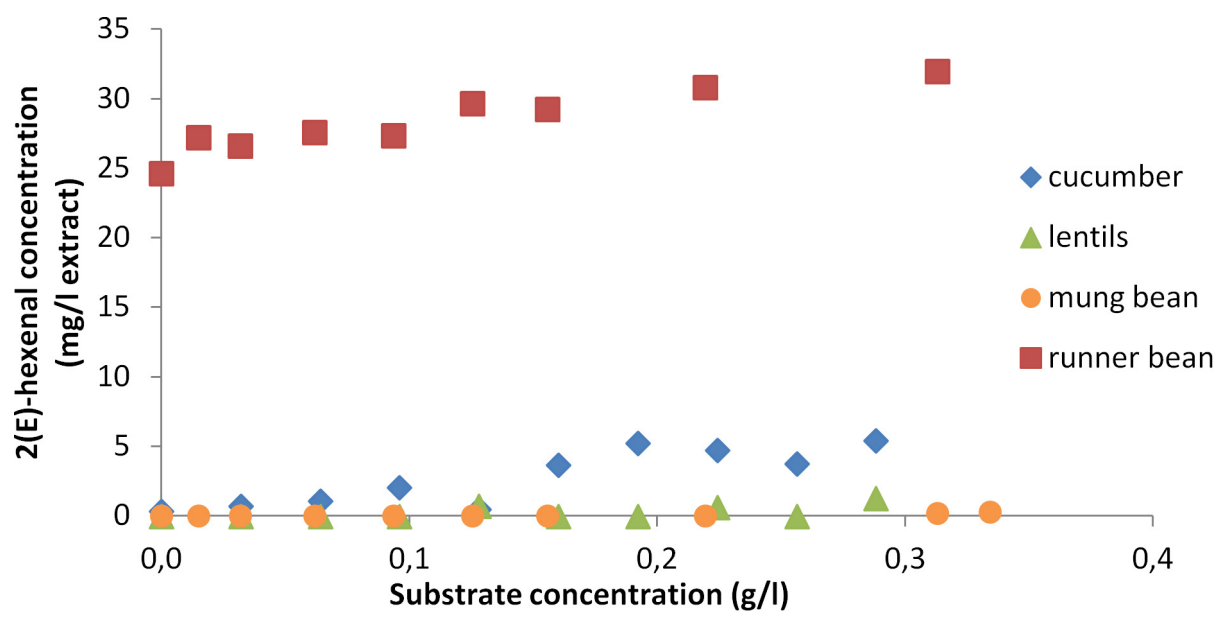

Fig. 5. Formation of 2(E)-hexenal concentration in dependence on substrate concentration (13-HPOT).

1-hexanol. The content of 1-hexanol is therefore endogenous. A significant difference in the formation 2(E)-hexenal was observed between runner bean leafs and other plant sources. The increase in the product concentration was however still rather small and corresponded to low substrate conversions.

The enzyme could have been inactivated very fast before appreciable conversion was achieved. Hydroperoxide lyase is a fragile enzyme that is very susceptible to substrate inactivation (Gigot et al. 2010). A higher substrate concentration thus leads to decreased performance. While 2(E)-hexenal concentrations in extract were similar in the range of concentrations used, lower substrate concentrations were more favourable in terms of substrate conversion. Based on these experiments, enzyme inactivation caused by substrate could not be distinguished from the enzyme instability caused by homogenisation or other factors.

\section{Biomass homogenate storage stability}

In large-scale C6-volatiles production, one of the greatest obstacles of using fresh plant material for enzymatic transformation is the availability of the plant biomass throughout the year. For this purpose, we have tried to distinguish whether a cold storage or freezing storage is sufficient to keep HPL activity at least for the short-term. For the cold storage experiment, runner bean leaves were harvested and homogenised as described above. Tab. 3 shows that HPL activity of fresh biomass was not preserved during cold storage.

For the freezing experiments with bean leaf biomass, the following procedure was performed: pre-cut leaves (about $20 \mathrm{~g}$ ) were divided into 2 parts; one third was put into the freezer $\left(-20^{\circ} \mathrm{C}\right)$ in a sealed bag and the rest was homogenized as described in the Materials and methods section. The homogenate was divided into halves, from which one was also frozen and the rest was used for the 
Tab. 3. Runner bean leaves cold-storage experiments.

\begin{tabular}{cccc}
\hline $\begin{array}{c}\text { Time of storage } \\
\mathrm{h}\end{array}$ & $\begin{array}{c}\text { 13-HPOT concentration } \\
\mathrm{mg} / \mathrm{l}\end{array}$ & $\begin{array}{c}\text { Total 2(E)-hexenal } \\
\mathrm{mg}\end{array}$ & $\begin{array}{c}\text { 2(E)-hexenal concentration } \\
\mathrm{mg} / \mathrm{l}\end{array}$ \\
\hline 0 & 0 & 0.047 & 11.9 \\
0 & 18.2 & 0.050 & 12.4 \\
0 & 28.6 & 0.045 & 11.3 \\
1 & 0 & 0.035 & 8.6 \\
1 & 20.1 & 0.034 & 8.4 \\
3 & 0 & 0.039 & 9.7 \\
3 & 20.1 & 0.039 & 9.1 \\
24 & 0 & 0.036 & 8.7 \\
\hline
\end{tabular}

Tab. 4 Runner bean leaves freeze-storage experiments.

\begin{tabular}{lccc}
\hline Sample & $\begin{array}{r}\text { 13-HPOT concentration } \\
\mathrm{mg} / \mathrm{l}\end{array}$ & $\begin{array}{c}\text { Total 2(E)-hexenal } \\
\mathrm{mg}\end{array}$ & $\begin{array}{c}\text { 2(E)-hexenal concentration } \\
\mathrm{mg} / \mathrm{l}\end{array}$ \\
\hline Fresh homogenate & 0.0 & 0.069 & 17.2 \\
Fresh homogenate & 25.3 & 0.067 & 16.9 \\
Fresh homogenate & 45.3 & 0.063 & 15.6 \\
Frozen homogenate & 0.0 & 0.110 & 27.6 \\
Frozen homogenate & 32.5 & 0.105 & 26.3 \\
Frozen homogenate & 47.9 & 0.102 & 25.6 \\
Frozen leaves & 0.0 & 0.031 & 7.7 \\
Frozen leaves & 37.9 & 0.031 & 7.8 \\
Frozen leaves & 55.2 & 0.032 & 7.9 \\
\hline
\end{tabular}

control measurement. The control measurement was accomplished immediately after homogenisation. After three weeks of storage at $-20{ }^{\circ} \mathrm{C}$, the leaves and the homogenate were thawed and used for HPL reaction as described above.

Table 4 presents similar negative effect of substrate concentration on the product yield as was presented above. It is also interesting to point out that after freezing, the homogenate had by $55 \%$ higher content of 2(E)-hexenal than that in the fresh homogenate. This effect was probably caused by the tearing effect of frost on cells that had not been disrupted during homogenisation. In case of frozen leaves, there was a decrease in product concentration compared to fresh leaves. Such an observation is in agreement with the results of cooling on the HPL stability. The activity loss can be attributed to several factors such as oxidation, protease activity, enzyme instability, lower water activity or $\mathrm{pH}$ changes that happen after picking the leaves from the plant. Many of these effects do not apply in a homogenate that is protected from $\mathrm{pH}$ change by a buffer and from metalloproteases by EDTA. The free $-\mathrm{SH}$ groups of dithiothreitol also enhance the protec- tive effects to the sensible surface of HPL. Freezing thus showed to be a good way for keeping the enzyme activity of homogenate for several weeks period.

\section{HPL localisation in plant cells}

To determine whether the HPL enzyme is bound to some cellular structures in bean leaf as was suggested for some plant species (Nuñez et al., 1998; Salas and Sánchez, 1999; Grechkin, 2002; Németh et al., 2004) or is free in the cytoplasm such as in the tea plant (Liu and Han 2010), a following procedure was performed. Runner bean leaves were harvested and homogenised in a buffer that did not contain Triton. Triton as a solubilisation detergent would not allow distinguishing bound and unbound enzyme. The filtered homogenate has undergone centrifugation (12 $000 \mathrm{rpm}$, $10 \mathrm{~min}$ ) and the supernatant was used without further modification. The pellet was transferred and re-suspended with homogenisation buffer to the same volume as supernatant $(3 \mathrm{ml})$. Both materials were used for the determination of HPL activity (Tab. 5). Higher activity was found for supernatants. 
Tab. 5. Summary of HPL solubilisation experiment.

\begin{tabular}{lcccc}
\hline \multirow{2}{*}{ Sample } & $\begin{array}{c}\text { 13-HPOT concentration } \\
\mathrm{mg} / \mathrm{l}\end{array}$ & $\begin{array}{c}\text { Pellet weight } \\
\mathrm{g}\end{array}$ & $\begin{array}{c}\text { Total 2(E)-hexenal } \\
\mathrm{mg}\end{array}$ & $\begin{array}{c}\text { 2(E)-hexenal concentration } \\
\mathrm{mg} / \mathrm{l}\end{array}$ \\
\hline Supernatant & 18.3 & $\mathrm{n} / \mathrm{a}$ & 0.079 & 19.73 \\
Supernatant & 32.0 & $\mathrm{n} / \mathrm{a}$ & 0.074 & 18.62 \\
Supernatant & 0.0 & $\mathrm{n} / \mathrm{a}$ & 0.061 & 15.20 \\
Pellet & 18.3 & 0.115 & 0.039 & 9.69 \\
Pellet & 32.0 & 0.146 & 0.036 & 8.97 \\
Pellet & 0.0 & 0.176 & 0.035 & 8.72 \\
\hline
\end{tabular}<smiles>Cc1cc(C(C)(C)C)c(O)c(C(C)(C)C)c1</smiles>

Fig. 6. Structure of BHT (butylated hydroxytoluene).

\section{Radical inhibitor influence test}

It has been reported that the true product of HPL cleavage is a hemiacetal (Grechkin, 2002; Stumpe and Feussner, 2006) which subsequently disintegrates. It has also been suggested that a formed radical damages the enzyme and causes its inactivation (Santiago-Gómez et al., 2007). To test this assumption and to resolve whether the presence of a radical inhibitor has any influence on the result of the reaction, butylated hydroxytoluene (Fig. 6) was chosen as a model agent that was added into the homogenisation buffer and dissolved with ultrasound to final concentrations up to $6 \mathrm{mmol} / \mathrm{l}$. Fig. 7 shows that the concentrations of the radical inhibitor between $1-3 \mathrm{mmol} / \mathrm{l}$ used had a slightly positive effect. The enzyme lifetime was extended by inhibiting excess radicals or eliminating a radical-enzyme complex and returning the enzyme to its original state. A similar effect of about $10-15 \%$ increase of the amount 2(E)-hexenal formed was reported by Xiong et al. (2012). In subsequent experiments, the method of enzyme preparation was modified so that BHT in the concentration of $2 \mathrm{mmol} / \mathrm{l}$ was added to the homogenisation buffer.

\section{Reaction time-course}

To investigate the reaction progress, the reaction was performed in a larger vessel volume then in previous experiments and samples were withdrawn at different times. The samples were immediately sealed, heated for 20 seconds in boiling water for enzyme deactivation and quickly cooled and stored on ice until analysis. A parallel experiment was per-

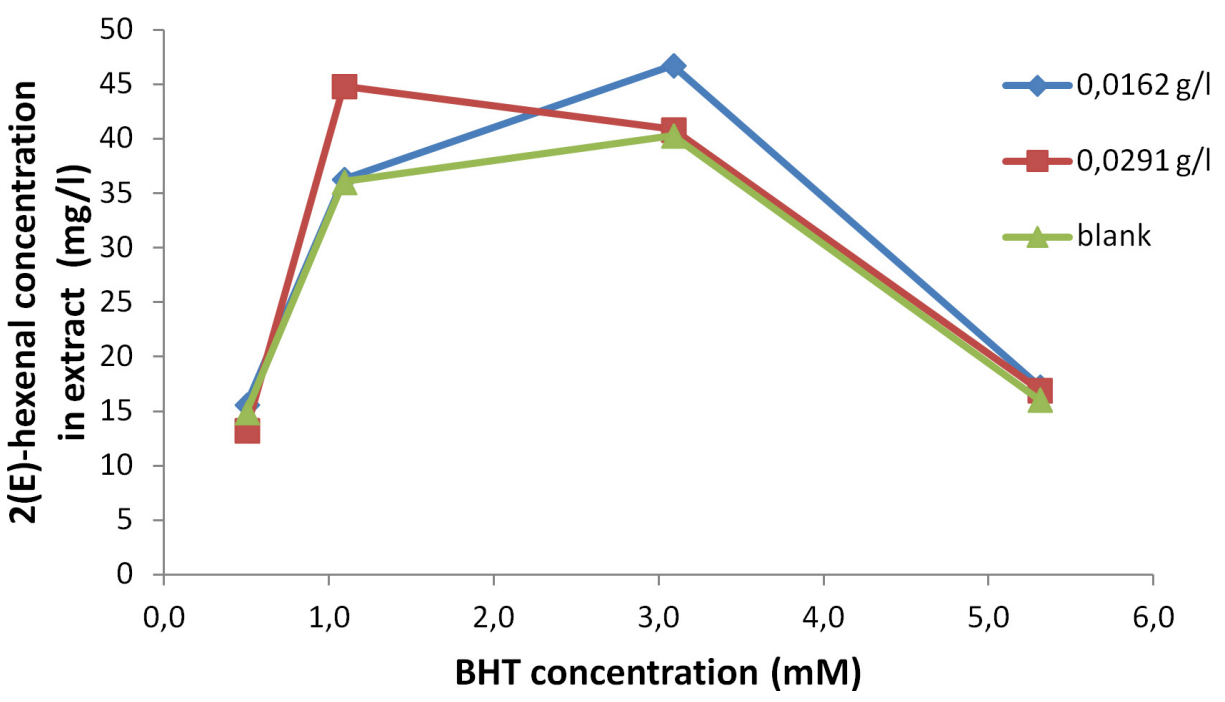

Fig. 7. Influence of radical inhibitor on the formation of 2(E)-hexenal. The lines represent different 13-HPOT substrate concentrations. 
formed concurrently where a blank substrate was used to consider endogenous product formation and evaporation from the vessel. The temperature of the reaction was set to $20^{\circ} \mathrm{C}$. During the progress of the reaction, a second dose of the substrate was added at a specific time point when the primary substrate was expected to be already consumed. The obtained progress curves are presented in Fig. 8. The measured concentration 2(E)-hexenal in the reaction mixture (diamonds) was corrected for evaporation from the blank experiment (squares). The true concentration courses are thus represented by the triangles signs. It appears that the product concentration slightly decreased first and afterwards slightly increased. The concentration did not change significantly after 10 minutes of the reaction. When the second portion of the substrate was added after 30 minutes, 2(E)-hexenal concentration changed only slightly. A plausible explanation is that the HPL lost the activity quickly.

Tab. 6 presents a comparison of the results achieved in this study with those presented in other publications. It is evident that much higher yields of 2(E)hexenal were achieved in some works. These data underscore the known experience that the production of plant enzymes depends very much on the plant variety, agricultural conditions and seasonal variations.

\section{Conclusions}

The results of experiments dealing with production of 2(E)-hexenal using different plants as a source hydroperoxide lyase enzyme are presented in this work. It was found that the runner bean (Phaseolus coccineus) leaves provided highest concentration of desirable product with an acceptable substrate conversion. However, there are certain disadvantages of using this material. The largest is the variability of the plant. The content of the enzymes varies significantly during the year and also with plant age. It also depends on the culture conditions such as soil quality, plant nutrition and light availability. More research would need to be done to provide all-year availability of the enzyme. Furthermore, a source of cheap linolenic acid is needed to provide sustainable process economics in case of larger scale production. It was found that the addition of

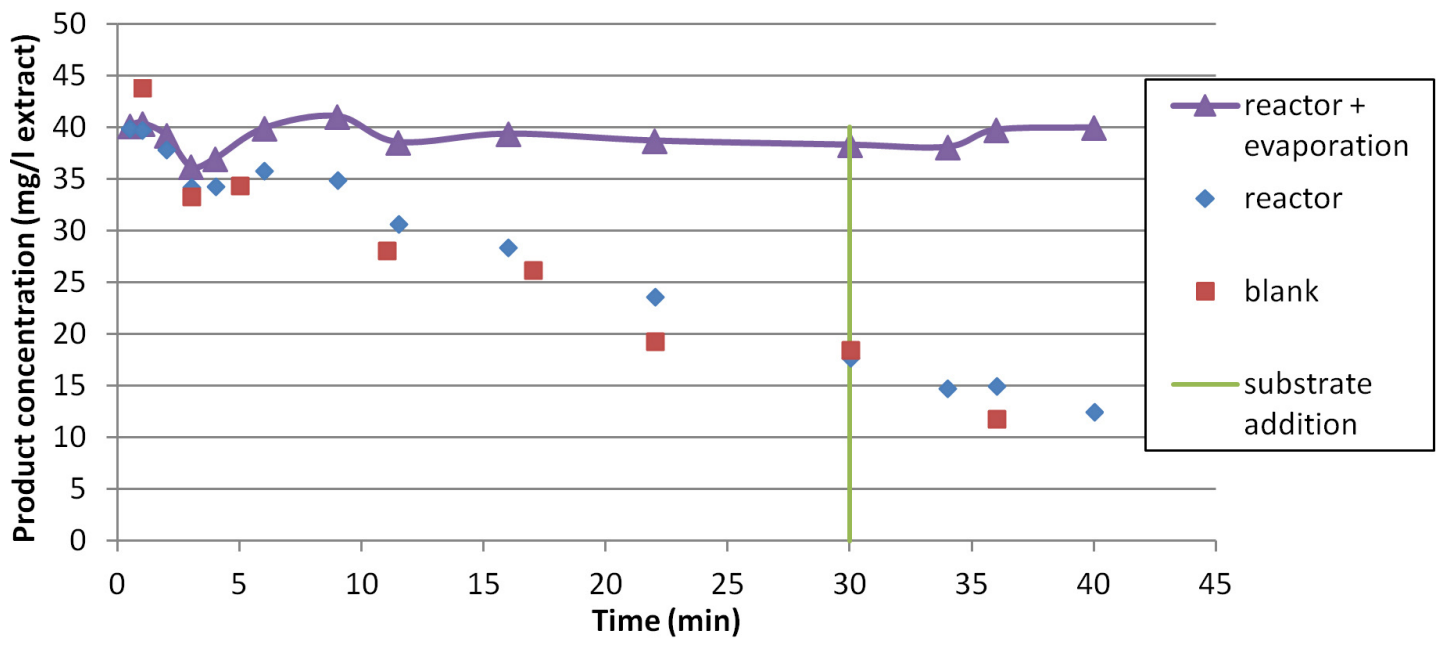

Fig. 8. Course of 2(E)-hexenal formation.

Tab. 6. Comparison of published results on 2(E)-hexenal formation.

\begin{tabular}{lccc}
\hline Plant & Substrate concentration & Product concentration & Reference \\
\hline Runner bean & $0.03 \mathrm{mmol} / \mathrm{kg}^{*}$ & $36 \mathrm{mg} / \mathrm{kg}^{*}$ & This article \\
Mung bean & $32 \mathrm{mmol} / \mathrm{kg}^{*}$ & $0.47 \mathrm{mM}$ & Rehbock et al. (1998b) \\
Amaranth & $30 \mathrm{mM}$ & $1100 \mathrm{mg} / \mathrm{kg}^{*}$ & Xiong et al. (2012) \\
Chilli pepper & $\mathrm{n} / \mathrm{p}$ & $450 \mathrm{mg} / \mathrm{L}$ & Husson et al. (2002) \\
Olive & $0.5 \mathrm{mM}$ & $0.29 \mathrm{mg} / \mathrm{g}^{*}$ & Akacha \& Gargouri (2009) \\
Mint & $5-10 \mathrm{mM}$ & $0.05 \mathrm{mmol} / \mathrm{l}$ & Gargouri et al. (2004) \\
Common bean & $\mathrm{n} / \mathrm{p}$ & $1160 \mathrm{mg} / \mathrm{kg}^{*}$ & Ogura (1997) \\
\hline
\end{tabular}

$\mathrm{n} / \mathrm{p}$ - not provided, ${ }^{*}$ per kg of fresh biomass, ${ }^{*}$ per gram of protein. 
radical inhibitor can slightly improve the enzyme stability. To avoid detrimental effect of substrate on hydroperoxide lyase the use of fed-batch reactor with low volumetric flow of the substrate feed could be beneficial.

Acknowledgement

This article was created with the support of the Ministry of Education, Science, Research and Sport of the Slovak Republic within the Research and Development Operational Programme for the project "University Science Park of STU Bratislava”, ITMS 26240220084, co-funded by the European Regional Development Fund.

\section{Abbreviations}

BHT butylated hydroxytoluene (2,6-bis(1,1dimethylethyl)-4-methylphenol)

DTT dithiothreitol ((2S,3S)-1,4-bis(sulfanyl) butane-2,3-diol)

HPL hydroperoxide lyase

LeA linolenic acid ((9Z,12Z,15Z)-9,12,15octadecatrienoic acid)

LiA linoleic acid ((9Z,12Z)-9,12-octadecadienoic acid)

LOX lipoxygenase

PBS phosphate buffer solution

13-HPOT 13-hydroperoxide of linolenic acid

13-HPOD 13-hydroperoxide of linoleic acid

\section{References}

Akacha NB, Gargouri M (2009) Process Biochemistry 44: 1122-1127.

Bourel G, Nicaud JM, Nthangeni B, Santiago-Gomez P, Belin JM, Husson F (2004) Enzyme and Microbial Technology 35: 293-299.

Buchhaupt M, Guder JC, Etschmann MMW, Schrader J (2012) Applied Microbiology and Biotechnology 93: $159-168$.

Fauconnier ML, Marlier M (1997) Grasas y Aceites 48 30-37.

Gardner H (1996) Journal of the American Oil Chemists' Society 73: 1347-1357.
Gargouri M, Drouet P, Legoy MD (2004) Journal of Biotechnology 111: 59-65.

Gigot C, Ongena M, Fauconnier ML, Wathelet JP, Du Jardin P, Thonart P (2010) Biotechnologie Agronomie Societe et Environnement, 14: 451-460.

Gomi K, Yamasaki Y, Yamamoto H, Akimitsu K (2003) Journal of Plant Physiology 160: 1219-1231.

Grechkin AN (2002) Prostaglandins \& Other Lipid Mediators 68-69: 457-470.

Havkin-Frenkel D, Belanger FC (2008) Biotechnology in Flavor Production, Blackwell Publishing, Oxford

Hui YH (2010) Handbook of fruit and vegetable flavors, John Wiley \& Sons, New Jersey.

Husson F, Belin JM (2002) Journal of Agricultural and Food Chemistry 50: 1991- 1995.

Janeš D, Kantar D, Kreft S, Prosen H (2009) Food Chemistry 112: 120-124.

Liu S, Han B (2010) BMC Plant Biology 10: 228.

Matsui K, Shibutani M, Hase T, Kajiwara T (1996) FEBS Letters 394: 21-24.

Németh ÁS, Márczy JS, Samu Z, Hager-Veress A, Szajani B (2004) Enzyme and Microbial Technology 34: $667-672$.

Nuñez A, Foglia TA, Piazza GJ (1998) Lipids 33: $533-538$

Ogura T (1997) Dynamic Aspects of Natural Products Chemistry, CRC Press, Boca Raton.

Perez-Gilabert M, Francisco-Garcia C (2002) Analytica Chimica Acta 465: 319-335.

Rehbock B, Gansser D, Berger RC (1997) Lipids 32: 1003-1010.

Rehbock B, Berger R (1998) Biotechnology Techniques 12: 539-544.

Rehbock B, Gansser D, Berger RC (1998) Food Chemistry 63: 161-165.

Salas JJ, Sánchez J (1999) Plant Science 143: 19-26.

Santiago-Gómez MP, Vergely C, Policar C, Nicaud JM, Belin JM, Rochette L (2007) Enzyme and Microbial Technology 41: 13-18.

Shibata Y, Matsui K, Kajiwara T, Hatanaka A (1995) Plant and Cell Physiology 36: 147-156.

Surburg H, Panten J (2006) Common Fragrance and Flavor Materials, $5^{\text {th }}$ ed., Wiley-VCH, Berlin.

Stumpe M, Feussner I (2006) Phytochemistry Reviews 5: $347-357$.

Xiong J, Kong XZ, Zhang CM, Chen JM, Hua YF (2012) European Food Research and Technology 235: 783-792. 